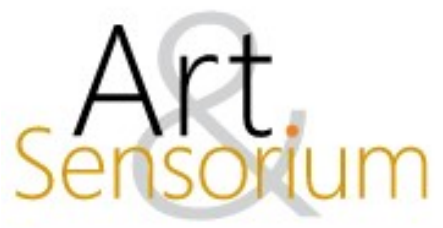

\title{
A CARTOGRAFIA COMO POSSIBILIDADE DE PESQUISA EM ARTES
}

https://doi.org/10.33871/23580437.2021.8.1.315-330

Gustavo Falabella 1

Djalma Thürler ${ }^{2}$

\begin{abstract}
Resumo: Este ensaio faz pensar a questão da cartografia, em suas formas tradicionais ou mais contemporâneas, enquanto processo metodológico específico de pesquisa em artes. Rejeitando soluções instrumentais ou objetivas para os problemas, a cartografia, a partir de Gilles Deleuze, propõe uma mudança de filosofia, uma renovação do conteúdo dos mapas, espécie de contra mapeamento que articula uma lógica empírica de relações externas e uma prática não representativa de conhecimento.
\end{abstract}

Palavras-chave: Metodologia, Cartografia; Subjetividade, Artes.

\section{CARTOGRAPHY AS A POSSIBILITY FOR ARTS RESEARCH}

\begin{abstract}
This essay discusses the issue of cartography, in its traditional or more contemporary forms, as a specific methodological process of arts research. Rejecting instrumental or objective solutions to problems, cartography, from Gilles Deleuze on, proposes a change of philosophy, a renewal of the content of maps, a kind of counter-mapping that articulates an empirical logic of external relations and a non-representational practice of knowledge.
\end{abstract}

Keywords: Methodology, Cartography; Subjectivity, Arts.

\section{LA CARTOGRAFÍA COMO POSIBILIDAD DE INVESTIGACIÓN EN LAS ARTES}

Resumen: Este ensayo nos hace reflexionar sobre la cuestión de la cartografía, en sus formas tradicionales o más contemporáneas, como proceso metodológico específico de la investigación en artes. Rechazando las soluciones instrumentales o objetivas a los problemas, la cartografia, a partir de Gilles Deleuze, propone un cambio de filosofía, una renovación del contenido de los mapas, una especie de contramapa que articula una lógica empírica de las relaciones externas y una práctica no representativa del conocimiento.

Palabras clave: Metodología, Cartografía; Subjetividad, Artes.

\footnotetext{
${ }^{1}$ Doutorando do Programa de Pós-graduação em Cultura e Sociedade (IHAC/UFBA), bolsista FAPESB. Integrante da Linha Culturas e Cidade do NuCuS. Salvador. Brasil. https://orcid.org/0000-0002-0512-8412. gfalabellarocha@gmail.com

2 Professor Permanente do Programa de Pós-graduação em Cultura e Sociedade (IHAC/UFBA). Pesquisador do NuCus. Salvador. Brasil. https://orcid.org/0000-0002-9161-0300.djalmathurler@ufba.br
} 


\section{Rizomas, decalques e cartografias}

"Tudo, aliás, é a ponta de um mistério, inclusive os fatos. Ou a ausência deles. Duvida? Quando nada acontece, há um milagre que não estamos vendo"

(Guimarães Rosa).

A cartografia tornou-se uma prática popular e muito comentada nas Ciências Sociais, Humanidades e nas Artes. Embora o mapeamento seja frequentemente utilizado para fornecer uma visão global de uma ideia ou para esclarecer uma situação, gostaríamos de argumentar que pode ser uma atividade muito mais complexa, que escapa à representação habitual e toca o núcleo dos processos criativos, quer sejam de ordens artísticas ou conceituais.

Na perspectiva de uma geografia mais clássica, os mapas são representações dignas de confiança para o pesquisador - e também para os leigos - . A representação em escala cartográfica - lê-se mapas se vale de uma visão do alto e de longe para plasmar territórios e, assim, determinar suas representações. Historicamente, tais representações ganharam ferramentas tecnológicas muito úteis para tentar se aproximar da realidade: os satélites, por exemplo, permitem visões áreas de muito longe e contribuem para esse olhar vertical da geografia e seus mapas. Como veremos adiante, os satélites e os aplicativos de mapeamento fazem parte cotidiana da vida das pessoas, nos dispositivos eletrônicos que carregamos sempre no bolso ou na bolsa.

Por outro lado, se a geografia calcada nos mapas escalares evolui paulatinamente com os dispositivos tecnológicos, outras abordagens de território também ganharam espaço para problematizar o imperativo deste olhar vertical e sua onisciência. Uma visada geográfica que está mais interessada naquilo que ocorre na pressa e na agilidade das rotinas, os movimentos, pulsões e fluxos que se dão na escala 1 x 1 e que estão totalmente situados no tempo. Como esperamos argumentar, tempo e espaço estão unidos como dois lados de uma mesma moeda: o tempo, senhor das coisas, seguirá atuando nos lugares que nos interessam e, portanto, os seguirá modificando, mesmo quando nada acontece, como antecipa a fala de Guimarães Rosa (2006) utilizada neste ensaio à guisa de epígrafe.

Parece-nos impossível, para modos de começar, não abordar as provocações de Deleuze e Guattari (2011) acerca da cartografia. Em "Mil platôs", embora os mapas desempenhem um papel discreto, e não menos importante, como formas rizomáticas de escapar à representação, julgamos que devemos decupar melhor a ideia de rizoma e suas múltiplas possibilidades. Guattari e Deleuze argumentam que o pensamento tradicional, que eles criticam, é arborescente, no sentido em que segue um padrão linear, ramificando-se em vários pontos. Os rizomas, resultantes de uma espécie de sistema radicular encontrado na natureza, são não lineares e não hierárquicos. Sendo um processo não hierárquico, o rizoma não é, portanto, um objeto de representação.

Visualmente não é possível saber onde começa a estrutura e onde ela termina, por isso, os mapas são orientados para a experimentação, porque a estrutura, o rizoma, é um meio, uma experiência, não se reproduz (DELEUZE; GUATTARI, 2011). Deleuze e Guattari, ao esmiuçarem o rizoma em alguns princípios, chamam atenção para os de conexão e de heterogeneidade - que são capazes de conectar qualquer ponto do rizoma, que "é muito diferente da árvore ou da raiz que fixam um ponto, uma ordem" (Idem, 2011, p. 14) - que renovam, portanto, a forma como pensamos a subjetividade em suas dimensões imanentes e performativas. 
A comparação entre árvores e rizomas é recorrente, já que eles entendem que as árvores - enquanto metáfora de metodologias e processos - são restritivas, uma vez que toda a cultura, da biologia à linguística, é fundada nas estruturas de árvores e/ou raízes. Não se deve acreditar mais em raízes, radículas ou árvores, "ao contrário, nada é belo, nada é amoroso, nada é político a não ser que sejam arbustos subterrâneos e as raízes aéreas, o adventício e o rizoma" (Idem, 2011, p. 24). A árvore, segundo eles, aceita a ordem das coisas, remete a processos reprodutíveis, modelos decalcados que podem ser repetidos à exaustão, ao infinito. O decalque, aliás, será uma noção importante na transição entre rizoma e cartografia.

Para Deleuze e Guattari, o rizoma traz mais possibilidades e complexidades que se relacionam de forma mais potente com os campos dos saberes e da criatividade. Sem centro, sem núcleo, sem indicativo por onde se deve começar ou analisar, um rizoma dá ao pesquisador mais possibilidades e responsabilidades. É justamente neste campo permeável, aberto e performativo que a ideia de rizoma se encontra com as possibilidades da cartografia feita de forma horizontal, "não somente como método da geografia clássica territorial, mas como tática micropolítica cotidiana composta pela ação política; um fazer insurgente, dinâmico, sempre processual e criativo" (RENA etal, 2016, p. 15), "que, ao invés de procurar por alguma raiz e/ou origem de um fenômeno, está mais interessado em estabelecer ou evidenciar conexões de aspectos que se ligam e se ramificam infinitamente" (COLLING, 2021, p. 27-28), sem recorrer aos instrumentos verticais de representação do espaço como verdades fixas. Pensado assim, o mapa não diria simplesmente respeito a "movimentos", como um conhecimento que permaneceria exterior ao seu objeto; ele faz o movimento acontecer, e ajuda a torná-lo realidade, "tout entière tournée vers une expérimentation en prise sur le réel ${ }^{3 "}$ (DELEUZE; GUATTARI, 1980, p. 20).

É curioso, mas não é coincidência, supomos, que o rizoma se oponha à árvore, na mesma medida que o olhar horizontal que desejamos se oponha à platitude do olhar vertical. Aproximando o rizoma dos mapas, os dois pesquisadores pontuam que

o mapa é aberto, é conectável em todas as suas dimensões, desmontável, reversível, suscetível de receber modificações constantemente. Ele pode ser rasgado, revertido, adaptar-se a montagens de qualquer natureza, ser preparado por um indivíduo, um grupo, uma formação social. Pode-se desenhá-lo numa parede, concebê-lo como obra de arte, construí-lo como uma ação política ou como uma meditação. (DELEUZE e GUATTARI, 2011, p. 21).

Os mapas, assim, sem entradas pré-definidas, oferece ao pesquisador "múltiplas entradas", um novo tempo para as presenças próximas que as desenham, espaço da criatividade, uma "questão de performance" (DELEUZE; GUATTARI, 2011, p. 21), ao contrário do decalque, que volta sempre ao mesmo ponto. O mapa, não, ao propor uma experiência ancorada no real, a fím de explorar territórios existenciais, transbordam indivíduos e os seus corpos, tornando-se instrumentos para ir além da própria história individual. Não é um instrumento de reflexão, mas de mobilização; não é um meio de reproduzir uma realidade supostamente pré-existente, mas um operador de exploração e descoberta criativa de novas realidades. Em suma, os mapas são vetores de multiplicação que promovem uma intensificação da experiência comum e não são reabsorvidos numa unidade padronizada.

Os mapas fazem existir multiplicidade de dimensões que permitem a criatividade estética, "uma estética que valoriza o ato de criação, da revolução criadora" (PERES; BORSONELLO; PERES, 2000, p.37), relativamente aos caminhos através dos quais (damos) sentido (ao) mundo, ou seja, há a sugestão de que a cartografia exige um relato estético das nossas experiências e, neste sentido, os mapas funcionariam como um meio de experimentação para um encontro entre arte, filosofia e

\footnotetext{
3 "inteiramente voltada para uma experimentação em contato com o real". Tradução nossa.
} 
política, aliás, a luta pela preservação dessas multiplicidades de unificação não pode ser outra coisa senão política, sendo

possível imaginar a cartografia para além de ser um método de investigação que envolve uma experiência cotidiana, dissolvendo as relações entre micro e macropolítica, entre sujeito pesquisador e objeto pesquisado, e existindo como um dispositivo que compõe as metodologias e as estratégias como maquinação e agenciamento de ações de copesquisa ativista. Um dispositivo é composto por linhas de subjetivação e é também um processo, uma produção de subjetividade. (RENA, SÁ, BRUZZI, QUINTÃO, 2016, p.14).

Rizomas, mapas e decalques serão aplicados por Deleuze e Guattari para debater e problematizar postulados e práticas sociais, estéticas ou políticas, ou mesmo de práticas psíquicas, simbólicas ou imaginárias. No campo da psicanálise, por exemplo, oferece a esquizoanálise como uma alternativa, "uma espécie de 'caixa de ferramentas' que pode inspirar uma compreensão dos fenômenos psicosociais-históricos-políticos e agenciar práticas que fujam à ordem cotidiana, rompendo com os saberes instituídos em troca de um saber subterrâneo" (NAVARRO, s/d, s/a), mais rizomático da interpretação psíquica. Dessas provocações surgem diversos estudos cartográficos, no campo da psicanálise e da psicologia, como é o caso de Suely Rolnik, que teve relação produtiva e direta com Guattari em suas formulações a respeito do afeto e da proximidade com o outro. Virgínia Kastrup, Eduardo Passos e outros tantos pesquisadores bebem da mesma fonte e aprofundam suas cartografias inspiradas na ideia rizomática dos pensadores franceses, mas, também reconhecendo o caminho percorrido no Brasil, por Suely Rolnik.

Em suas 'Notas de Abertura', de "Cartografia Sentimental", Rolnik demonstra seus interesses de pesquisa e destina poucas linhas à cartografia clássica da geografia. Ela irá aproximar o termo cartografia dos seus problemas de pesquisa, dizendo que "paisagens psicossociais também podem ser cartografáveis" (ROLNIK, 2011, p. 23). Tais cartografias se fazem com o desmoronamento de alguns mundos para emersão de outros "[...] mundos que se criam para expressar afetos contemporâneos, em relação aos quais universos vigentes tornaram-se obsoletos" (Ibidem). Fica evidente que a autora se interessa por processos provisórios, em curso, enquanto ela própria escrevia suas formulações. Naquilo que ela chama de definição provisória da cartografia, ela aconselha que - sendo o cartógrafo responsável por vocalizar afetos que pedem passagem - "“...] dele se espera basicamente que esteja mergulhado nas intensidades de seu tempo e que, atento às linguagens que encontra, devore as que lhe parecerem possíveis para a composição das cartografias que se fazem necessárias. O cartógrafo é, antes de tudo, um antropófago" (Ibidem).

A sensibilidade do cartógrafo, contudo, não será capaz de evitar a impermanência do seu próprio trabalho. Cartografar é interferir em um mundo que está em construção, um porvir, um processo inacabado de abordagem de processos, como um caminho possível forjado no encontro entre narrativas e trajetórias heterogêneas. Processos e não resultados.

Se pensarmos que as cartografias são retratos dessa interação no tempo e espaço, entenderemos sua característica provisória e, portanto, a impossibilidade de fixação que os mapas verticais pretendem. Sobre seu trabalho em "Cartografia Sentimental", Rolnik (2011) diz que ele se compôs enquanto alguns afetos foram (re)visitados e ressignificados. Consequentemente, um território se compôs por meio deles. As ressignificações são provisórias e só funcionam até que se invente novas cartografias e novos mundos (ROLNIK, 2011, p. 26).

O método da cartografia requer a habitação de um território. Em "Cartografar é traçar um plano comum”, Virgínia Kastrup e Eduardo Passos (2013) afirmam que a cartografia deve reunir os diferentes vetores heterogêneos implicados na pesquisa, entre outras coisas, sujeitos e objetos, 
humanos e não-humanos. O plano pode ser chamado de comum porque opera comunicação entre singularidades heterogêneas, num plano que é pré-individual e coletivo.

\begin{abstract}
A pesquisa cartográfica faz aparecer o coletivo, que remete ao plano ontológico, enquanto experiência do comum e, dessa maneira, é sempre uma pesquisa-intervenção com direção participativa e inclusiva, pois potencializa saberes até então excluídos, garante a legitimidade e a importância da perspectiva do objeto e seu poder de recalcitrância. O plano comum que se traça na pesquisa cartográfica não pode, de modo algum, ser entendido como homogeneidade ou abrandamento das diferenças entre os participantes da investigação (sujeitos e coisas). Como pensar, então, o comum na diferença? Como pensar o plano comum do heterogêneo? (KASTRUP; PASSOS, 2013, p. 266).
\end{abstract}

Nota-se, pois, que a prática cartográfica não é apenas uma transcrição do território, mas também uma participação ativa em sua realização atravessada por algumas sub questões: Como produzir um território comum? Como mudar a nossa visão diária do território? Que atitude adotar quando nos encontramos, exploramos e medimos o terreno a ser cartografado? Os autores indicam, no contexto da cartografia, que o comum é produzido pela transversalização de práticas como participação, inclusão e tradução e afirmam o paradoxo que não permite separar as ideias de comum e heterogeneidade. Assim, portanto, a pesquisa científica em artes, à luz da cartografia, se equilibra no tênue limite entre o que é compartilhado e aquilo que difere e tensiona, entre as regulações de conhecimento e os mergulhos da experiência.

Kastrup e Passos (2013) nos dizem que é impossível evitar a tensão entre essas duas direções: o universal que regula um sentido lógico, por vezes generalista, e o comum, calcado na experiência. $\mathrm{O}$ comum se define por sua consistência experiencial, jamais definitivo. $O$ comum não se fixa e não sendo algo dado ou posto, é acompanhado de práticas compartilhadas que comunam e criam o efeito de pertencimento, do bem comum, tratando-se, pois, de um conceito político por excelência, uma vez que somos convocados a tomar decisões e fazer partilhas no coletivo, afinal "entre o lógico (universal) e o político (comum) define-se, portanto, uma diferença de direção na experiência - à montante e à jusante dela - o que nos permite pensar uma coexistência que não abole a fricção e na qual o esforço de construção marca presença" (KASTRUP e PASSOS, 2013, p. 267).

Mas qual é o tipo de participação possível em uma pesquisa para fazer com que ela esteja em um campo comum? Rolnik nos diz que o olhar sobre o campo do pesquisador não deve ser daqueles que "se debruçam sobre", mas "constroem junto com" (2011, p. 15), o que coaduna com Kastrup e Passos (2013), para quem a prática de cartografar passa por uma pesquisa com seus interesses e não sobre seus interesses. Pode parecer mero jogo de palavras, mas na prática, um pesquisador é alguém que está aberto às interferências não esperadas da pesquisa, está aberto ao imponderável, ao não imaginado. Pensada assim, a cartografia deixa de ser simplesmente uma questão de descrever e justificar a utilização deste ou daquele instrumento. Kastrup e Passos falam ainda de uma transversalidade para estabelecer o comum, destacando que "a cartografia é pesquisa-intervenção participativa porque não mantém a relação de oposição entre pesquisador e pesquisado tomados como realidades previamente dadas, mas desmancha esses polos para assegurar sua relação de coprodução ou co-emergência" (KASTRUP, PASSOS, 2013, p. 270-71).

Ainda sobre a participação e relação do pesquisador e seu campo, segundo Kastrup e Passos (2013), a prática cartográfica se ancora em uma tríplice inclusão. A primeira delas dispõe os diferentes sujeitos e objetos implicados em uma linha transversal, sem hierarquias. Consequentemente, a falta de hierarquia - em contextos sociais premidos, regidos e acuados pela verticalidade hierárquica tende a gerar problemas, uma vez que pode gerar o que Nunes (2016) chama de horizontalismo, isso 
é, um desejo tão premente de dar voz para os diferentes que faz com que as diferenças sejam mais contundentes e fortes a ponto de inviabilizar o diálogo e o campo comum. A segunda inclusão diz respeito à capacidade do pesquisador em analisar criticamente seus objetos de interesse. Uma pesquisa tão implicada irá testar diuturnamente as convicções, pressupostos e os métodos do pesquisador. Kastrup e Passos ponderam que é importante não perder de vista a recalcitrância ${ }^{4}$ do objeto, na pesquisa. Finalmente, a terceira inclusão nos diz que a pesquisa se efetiva como uma experiência coletiva.

Kastrup e Barros (2015) ponderam que as pesquisas cartográficas são feitas de acompanhamento de processos, não de apresentação de objetos e a participação do cartógrafo deve ser de agenciamento, de composição entre heterogêneos. Assim, é fundamental entender o processo em sua processualidade, marcado por pulsões que trazem seu passado e contextos históricos, sociais, econômicos etc. Trata-se, nas palavras das autoras, de uma rede de forças, na qual o objeto está inserido-conectado e, portanto, de maneira bastante rizomática, cartografar é encontrar um ponto de entrada em contextos amplos e tentar construir de forma 'simpática' uma linha de pensamento que problematize os contextos imbricados a partir desta entrada. A simpatia é destacada como um componente importante para agenciar as relações entre pesquisadores e seus campos de interesse.

É um movimento de afeição mútua segundo elas, pois o cartógrafo se abre ao movimento de um território, imerso no plano das intensidades e, em seu "contato, varia, discerne variáveis de um processo de produção. Assim, detecta no trabalho de campo, no estudo e na escrita, variáveis em conexão, vidas que emergem e criam uma prática coletiva" (BARROS e KASTRUP, 2015, p. 74).

\section{Entre mapas e relatos}

[...] mapas não são considerados prontos nunca, mas continuamente re-feitos a cada vez que alguém se relaciona com eles, o que ressoa com a ideia de que mapas cognitivos estão sempre em movimento. Como os mapas estão sempre em um estado de se tornar algo, a cartografia deveria ser considerada como processual e não representacional (Kitchin e Dodge, 2007, p. 343). Essa perspectiva processual/nãorepresentacional levou à cartografia pós-representativa, que se move para além da oposição binária representativa ou não-representativa sem rejeitar a dimensão representativa dos mapas. De fato, essa abordagem não nega a importância das formas cartográficas, mas ao contrário enfatiza que tais formas não devem ser dissociadas do seu contexto de produção ou utilização (CAQUARD, 2016, p. 229. Tradução nossa).

Na passagem que abre esse item, o pesquisador Sébastien Caquard pondera que os mapas são mais comumente usados como ferramentas analíticas para a exploração das dimensões espaciais da narrativa, marcando a emergência de práticas híbridas como a cartografia literária, cartografia fílmica, geomídia, entre outras. Caquard, entre 2011 e 2016, compilou três relatórios nos quais analisa várias possibilidades de cartografias em um espectro bastante amplo das ciências. Baseado nesses relatórios, faremos uma aproximação do que nos interessa ao discutir cartografia em suas possibilidades de pesquisa mais subjetivas, mais próximas e afeitas ao campo das artes.

Segundo Caquard, os mapas verticais, apoiados pela necessidade moderna de medir, controlar e explorar demonstram sua força silenciosa e hegemônica, enquanto a virada crucial da cartografia

\footnotetext{
4 A recalcitrância nesse caso é a atitude de se apegar a uma ideia de pesquisa, seja do objeto, dos procedimentos metodológicos e afins e não conseguir adaptá-la aos contextos que a própria pesquisa pede/impõe. Uma espécie de conduta teimosa em relação ao devir-pesquisa. N.A.
}

R. Inter. Interdisc. Art\&Sensorium, Curitiba, v.8, n.1, p. 315 - 330 Jan.- Jun. 2021 
(considerando o advento e a adesão que os mapas subjetivos, narrativos, cognitivos ganharam) modificou dramaticamente as relações entre mapas e narrativas, seja desconstruindo e expondo as metanarrativas incorporadas nos mapas, seja projetando-os como uma forma potente de contar histórias.

Os mapas científicos ganharam importantes e decisivas ferramentas com os inúmeros aplicativos de localização presentes em cada dispositivo eletrônico. Ademais, Google Maps ou Bing Maps, por exemplo, criam uma área comum na qual o usuário pode atrelar suas postagens de redes sociais com sua localização. Levando em conta o GPS, é possível argumentar que os grid maps nunca foram tão importantes e populares. Por outro lado, é importante destacar as experiências dos navegantes longe das postagens e dos aplicativos, na vida real. Basicamente, o que tentamos pontuar aqui é que mesmo com a rotina integrada e vigiada do GPS, é bastante possível imaginar experiências criativas e práticas nos territórios de corpo presente. É fundamental que se pense nos mapas/cartografias como sistemas de navegação e não como representações miméticas. Caquard entende e sugere um caminho do meio, entre as narrativas e os mapas de grid:

Qualquer mapa pode tornar-se um estimulador de construção de histórias ou um limitador dependendo do contexto de sua utilização e aparição. Para mais, a distinção entre o mapa narrativo e o mapa de grid é borrada pelo fato de que eles coexistam, mais e mais, dentro de uma plataforma de mapeamento como Google Maps. Esse tipo de aplicativo estimula a produção de narrativas espaciais ao fazê-las fáceis de produzir e distribuir e, simultaneamente, restringem as narrativas pela estrutura proporcionadas pelos mapas de base. Uma questão que surge consistentemente ao longo desta revisão é a tendência em direção à hibridização: entre a cartografia e disciplinas criativas; entre os mapas de grid e os mapas narrativos; entre a ficção e a realidade; entre o mapa e o território (CAQUARD, 2011, p. 140. Tradução nossa).

É interessante pensar na comparação provocativa que ele faz entre os mapas de grid e os mapas narrativos, a partir de um paradoxo: quanto mais bem situado e orientado por mapas e coordenadas, mais perdido estará o navegante ${ }^{5}$, porque nossa relação com o mundo, vai dizer Caquard, deve ser de encantamento e, uma vez que se perde o encantamento, estamos perdidos. Ao relegar sua navegação a ferramentas tecnológicas como o GPS e afins, você pode poupar tempo, é certo, mas também te privará da experiência territorial imaginativa, mais subjetiva e criativa.

Assim, as emoções e o acaso não podem permanecer à sombra dessa metodologia, isto é, a trajetória do pensamento do cartógrafo é, em parte, determinada pelo que ele encontra em seu caminho, em um movimento de orientação-desorientação-reorientação (JACQUES, 2012), de perder-se para se encontrar, uma metodologia do devir. Essa relação, nomeada por RIFFAUD (2018) por flânerie sociológica, se baseia no princípio de que o trabalho de investigação requer deslo[u]camentos, vagabundagem, "isso porque a vagabundagem é afeto libertador, para quem aprende a olhar de soslaio e deslizar, gingar pelas frestas" (NASCIMENTO, 2020, p. 9) ou, nas palavras de Pascal Dibie, "flâner est une discipline, ne rien faire est un art, apprendre à regarder est une technique ${ }^{6}$ " (DIBIE, 1998, p. 174) e, por essas razões, significa, também, adotar a ideia de que o trabalho de investigação é composto e recomposto em cada momento. É pensar que o acaso não é nem mais nem menos do que

\footnotetext{
5 Navegante, andante, deambulante, pedestre, errante, transeunte, homem lento, praticante ordinário, sujeito corporificado, flâneur são alguns dos sinônimos que poderemos usar para nos referir às práticas espaciais que interessam a nossa pesquisa. Todas estas possibilidades advêm da leitura de estudiosos que pensaram as práticas destes arquétipos nos territórios. Embora possa haver distinção entre eles, entendemos que todos eles partem de noções irmãs/próximas e, assim, serão usadas como sinônimos ao longo do texto. N.A.
}

6 “vadiar é uma disciplina, não fazer nada é uma arte, aprender a olhar é uma técnica". Tradução nossa. 
uma forma particular de encontro e assumir esta postura corresponde andar à deriva, desafiando a onipresença da linha reta no mundo científico. É deliberadamente desviado, tortuoso e flutuante.

Contudo, não precisamos romantizar essa flânerie sociológica. Primeiro, não se deve confundir a flânerie sociológica com o zoning out (HATZFELD, 2009), não significa "confiar às estrelas" a tarefa de organizar o seu campo. Não é porque aquela aceita a influência do acaso e concede às emoções o estatuto de instrumento metodológico flexível que podemos confundi-la ou associá-la ao ócio desprovido de rigor. A flânerie sociológica requer um elevado nível de atenção, capacidade de resposta, ouvir os outros, mas, também, a si próprio e, também, disponibilidade a todo o momento ao inesperado. Aliás, são estes esforços que impedem que os dados escorreguem pelos dedos do investigador. É apenas com esta condição que a marcha permite estar aberto ao inesperado. Depois, lembrando de Certeau, é certo que todas as andanças devem ser acompanhadas pelas "astúcias criativas" (CERTEAU, 1994) de quem tem senso de preservação e segurança. É importante tomar cuidado por onde se desloca e por onde se perde. Alguns territórios podem ser hostis e perigosos.

\section{Cartografia pós-representativa: o caminho do meio}

Para Caquard, os mapas $\operatorname{cognitivos}^{7}$ podem ser um meio do caminho entre duas abordagens antagônicas: uma empírica, que considera os mapas na função técnica, de representação dos territórios, paisagens, lugares etc.; outra abordagem crítica, desenvolvida pelas ciências sociais e ciências humanas, que situa um mapa como ferramenta, relato, retrato das relações históricas de poder. Para o pesquisador, uma perspectiva pós-representativa seria o caminho híbrido, mas que nos lança uma pergunta: Como a cartografia pós-representativa pode contribuir para uma transformação das disputas e divisões entre práticas empíricas e teoria crítica?

O encontro entre cartografias empíricas e críticas traz, como dissemos, um paradoxo patrocinado pelas novas tecnologias de geoposicionamento: quanto mais técnico, menos autoral. Ou seja, as coordenadas e a precisão da localização podem ser bastante eficazes para situar um indivíduo, mas são ferramentas que roubam as possibilidades de navegação, que investidas da precisão técnica científica, não permitem ao navegador uma deambulação autoral e subjetiva nos espaços percorridos. Aos poucos, os aplicativos vão roubando a própria memória da experiência espacial, da flanêrie sociológica. Navegar com a salvaguarda do voice coach do Google Maps ou do Waze não permite ao andante a apreensão do espaço. De maneira relacional, as referências que nossa mente fazem costumam ser associativas, autorais e afetivas: Depois daquele prédio de arquitetura modernista, vire à direita pode se transformae em Em 300 metros, vire à direita. Por esse motivo é que Tim Ingold (2000) desafia a noção de que nosso pensamento se desenhe em mapas, como nos leva a crer alguns estudos em torno de mapas mentais e afins. Segundo ele, a mente funciona por rastros, referências, reminiscências e, portanto, o nosso pensamento é indicial, uma visão (de) dentro do mundo ( $a$ view in the world). Caquard nos lembra que as postulações de Ingold são diametralmente opostas ao que se costuma entender por mapas ou cartografia, que são tidos como não-indiciais. Isso é, uma visão do mundo (a view of the world). A saída mais fácil para esse paradoxo seria adotar uma visão a partir do mundo ( $a$ view from the world), isso é, por meio dos aplicativos ter experiências subjetivas, sensíveis, entre as duas extremidades do referido paradoxo. Porém, a interface virtual não substitui a experiência vivida, ela não pode ser considerada como uma possibilidade indicial de experiência

\footnotetext{
7 Segundo Caquard (2015) ele, se em um primeiro momento, ainda em 1950, os mapas cognitivos eram considerados simplórios e pouco críticos a processos sociais e históricos por sua abordagem mais comunicacional, mais recentemente eles se transformaram em possibilidade metodológica interessante para a cartografia, sobretudo ao considerarmos a importância que os sistemas de localização ganharam na rotina das pessoas. N.A.
}

R. Inter. Interdisc. Art\&Sensorium, Curitiba, v.8, n.1, p. 315 - 330 Jan.- Jun. 2021 
(INGOLD, 2000). Caquard nos dirá que tal paradoxo estimulou experiências antropológicas de campo baseadas nas relações cognitivas com mapas. Segundo ele, isso se aproxima da ideia de cartografia cognitiva pós-representativa.

Com a ideia de mapas sensíveis, ou da "potência específica do sensível" (ROLNIK, 2016, p. 12) podemos aproximar Caquard - e vários dos autores citados por ele - da ideia de cartografia sentimental, pensada por Suely Rolnik nos anos 1980, que destaca que o papel do cartógrafo "é dar língua para afetos que pedem passagem" (ROLNIK, 1987, p. 23), numa operação em que "o outro deixe de ser um objeto de projeção de imagens preestabelecidas (...) e possa se tornar uma presença viva, com a qual construímos nossos territórios de existência" (Idem, p. 12), por isso, talvez, os processos de mapeamento em campos se aproximem mais das ciências sociais e das artes dissidentes, já que podem se interessar por "matérias de qualquer procedência [...] [sem] racismo de frequência, linguagem e estilo" (Idem, p.24).

Pensando nos impactos da cartografia na pesquisa em artes, nos parece bastante oportuna a aproximação com a ideia de descrição densa, pensada por Clifford Geertz (1989) que, segundo Kastrup e Passos (2015), entende a importância de construir um campo comum nas suas pesquisas, maleável, adaptável aos contextos que se apresentam ao pesquisador. A descrição densa, em termos gerais, é uma ferramenta que tenta compor o cenário, as relações, os indivíduos de uma maneira bastante descritiva para que dessa descrição emerjam teorias, considerações e costuras, ela

contém em si uma microscopia interessada nos contextos obscuros, nos assuntos pequenos, nas chamadas miniaturas etnográficas. Nesse esforço de olhar através das frestas, maiúsculas são erigidas num processo que Geertz chama de "poder da imaginação científica". Despertar a experiência do mundo: desse fenômeno se ocupam as artes, as ciências, as filosofias, o senso comum (MARQUEZ, 2014, p. 13).

Geertz entende que as impressões de pesquisa, por esse olhar, venha "da delicadeza de suas distinções, não da amplidão de suas abstrações" (GEERTZ, 1989, p. 135). Em nossa compreensão, o aceno de Marquez à obra de Geertz é um passo importante para aproximar a cartografia da pesquisa de campo em artes, sobretudo na encruzilhada com os estudos sociais e antropológicos. Em "O mapa como relato", Marquez faz interessantes aproximações dos mapas com linguagens artísticas tomando como exemplo principal o livro "Os Autonautas da Cosmopista", escrito por Julio Cortázar e Carol Dunlop. Com uma estrutura de travelogue, o casal descreve a viagem feita de carro durante um mês, entre Paris e Marselha, na França. Ambos levam máquinas de escrever e descrevem cenários, sensações, capazes de construir um mapa imaginário e subjetivo de suas experiências entre as duas cidades. Segundo Marquez, a ideia de cartografia e de pluralidade heterogênea podem vir à tona, no desenho de outros mapas, mais performativos. Mapas do extravio, do desejo, mapas heterotópicos, que nos provocam a pensar que as narrativas a respeito do espaço são mais interessante que os territórios em si, uma vez que aqueles, enquanto cartografias, são elaborações estéticas daquilo que se experimenta no território, vocação que torna cada projeto de investigação extremamente singular e, portanto, qualquer desejo de reproduzir os resultados quase sempre é nulo, porque é difícil imaginar dois investigadores a caminharem o mesmo caminho da mesma maneira, seguindo os mesmos passos, o que revela o caráter inacabado e processual da cartografia, mais um manual de navegação, com alguns princípios, menos, propriamente, um retrato fixado das realidades e processos experienciados nos lugares narrados. 


\section{Metodologia das andanças: Derivas, Deambulações e Errâncias}

Essas considerações preliminares nos aproximaram de Certeau (1994) e do seu "investigador transitório", a partir de uma metodologia dos pés nos chãos ou metodologia das andanças, que se estabelece na prática de percorrer espaços da maneira lenta, como os homens lentos de Milton Santos (2006) ou os praticantes ordinários, do próprio Certeau. O "investigador transitório", que procura mover-se com os tempos em vez de correr contra eles, não procura estar em todo o lugar ao mesmo tempo, e está menos preocupado com o tempo que leva de um para outro lugar. Para além do dever de lentidão, o "investigador transitório" tem o dever de alternar fases de compromisso e distanciamento, como passos fundamentais para a produção científica.

Uma forma de narrar territórios que já não existem mais, que se dão na experiência de quem busca percorrê-los. Afinal, "os jogos dos passos moldam espaços. Tecem os lugares" (CERTEAU, 1994, p. 176). O historiador francês nos diz que a motricidade dos transeuntes forma um sistema real que se dá na prática, mas sem nenhum receptáculo físico, deixando rastros efêmeros apenas. Como, portanto, seria possível pensar em uma epistemologia que dá conta dessas experiências sensíveis, particulares, subjetivas? Como apreender, discorrer sobre algo tão fugaz? Esse é, pois, o dilema, ao que nos lançamos aqui. De saída, parece-nos importante pensar a pesquisa subjetiva em artes como uma prática dos pés nos chãos, em busca de "caminhos desviantes" ou "rotas alternativas" a partir de uma experiência singular (no sentido de única, a cada vez que se assume uma nova rota) que pode provocar, estimular caminhos outros para quem deseja devires nômades, afinal, são os caminhantes que atualizam os roteiros e rotas de uma cidade. São suas idas e vindas, com variações e improvisos que mudam ou deixam os elementos espaciais (CERTEAU, 1994).

Praticar espaços pode nos levar a pensar nas práticas culturais e artísticas das cidades, nas possibilidades de relação espacial que fujam àquelas mediadas e previstas pelos planos urbanísticos higienistas. Paola Berenstein Jacques (2012) nos fala em uma prática nômade de divagar e errar pela cidade, desafiando seus esquemas e mapas pré-definidos, destacando que os errantes não perambulam mais pelos campos, mas sim pelas grandes cidades, recusando o controle disciplinar dos planos modernos. Suas errâncias e nomadologias (DELEUZE E GUATTARI, 2012) se configurariam como uma denúncia das intervenções urbanísticas, do planejamento das cidades e seus espaços urbanos (JACQUES, 2012) que extirpam das grandes cidades as experiências mais subjetivas e nãocontroladas. Esse devir-nômade pode ser visto nas práticas, nas narrativas errantes de músicos, atores, performers, escritores e/ou pensadores "que subvertem a ordem imposta, criando "táticas [...] [para] jogar com os acontecimentos [...] [e transformá-los] em 'ocasiões"” (CERTEAU, 1994, p. 47). Em suas narrativas errantes, segundo Jacques (2012), é possível entender e apreender o espaço urbano de outras maneiras, "falar, ler, circular, fazer compras ou preparar as refeições etc.), [...] [como] vitórias do 'fraco' sobre o mais 'forte' [...], pequenos sucessos, artes de dar golpes, astúcias de 'caçadores' [...], simulações polimorfas, achados que provocam euforia" (CERTEAU, 1994, p. 47). É assim que, para Certeau, o "ato de caminhar está para o sistema urbano como a enunciação (o speech act) está para a língua [...]" (1994, p. 177), uma "enunciação pedestre".

A enunciação pedestre de Certeau se conecta com os fluxos e com as práticas da cidade (JACQUES, 2012;) sobretudo, porque ela - a enunciação - nos permite pensar em movimentos e formas não planejadas, quando olhamos os esquemas dos mapas originais. Também a caminhada "afirma, lança suspeita" (idem, p.179), tem o potencial de pensar uma metodologia com os pés no chão, em movimento, malandra, vadia e vagabunda (NASCIMENTO, 2020), sem fixar pontos e apostando nos fluxos que perpassam os lugares que nos interessam, "nas ruas que riem de nós quando procuramos alguma pureza e gargalham da nossa ingenuidade quando pensamos que o paiol colonial dominou 
tudo. Ruas que giram nossos sentidos quando achamos que apenas é possível caminhar num outro sentido" (NASCIMENTO, 2020, p.8).

Se concordarmos com Claude Eveno, que "a personalidade de uma cidade não é adquirida pela autoafirmação endógena, mas, gradualmente moldada por acidentes, oportunidades sucessivas e momentos propícios, através de encontros, visitas e viagens" (EVENO, 2001, p. 38), podemos pensar na ideia de uma metodologia das andanças, forjada por narrativas de corpo presente, situadas no tempo, buscando dialogar diretamente com as vicissitudes inerentes ao que vivemos durante a cartografia, o contrário do mapa tradicional, essa ilusão de espaço geométrico, dócil, imutável, uma fotografia do passado, um projeto político que busca impor limites, fronteiras artificiais que regulam e dizem quem é parte daquele recorte cultural, territorial e quem não é.

Para compor um processo metodológico cartográfico, devemos lançar mão de ferramentas e tecnologias de outros campos do conhecimento de maneira bastante intuitiva. Não significa, é bom que se diga, uma metodologia casuística ou oportunista. Oportunista, talvez, se pensarmos que aproveitamos as potencialidades de outros campos para ecoar nossos pensamentos e pulgas atrás da orelha, afinal, "existem tantas cartografias possíveis, quanto campos a serem cartografados" (FILHO; TETI, 2013, p. 46).

\section{Cartografias artísticas _ pistas para um método autoral}

Atualmente o método cartográfico tem sido muito utilizado por artistas na arte contemporânea, não apenas, pela "maneira como organizam e apresentam seus trabalhos, mostrando não só um objeto de pesquisa, mas também o percurso, os seus desdobramentos e a possíveis redes que a ele se conectam" (MOURA; HERNANDEZ, 2012, p. 2-3), "os rastros, as trilhas, o sulcar, a marca" (BOETTCHER, 2018 , p. 121), porque no mundo criativo das artes, os mapas e os processos de cartografia provaram ser material surpreendentemente fértil para expressões artísticas e intervenções sociais (COSGROVE, 2006), conforme atestam Fialho (2006) e Barbosa (2016). Enquanto a primeira afirma que "muitos artistas atuais se fascinaram pela riqueza formal e pelo significado social dos mapas" (FIALHO, 2006, p.9), o segundo atesta que o interesse dos artistas na cartografia estaria no seu caráter de desconstrução, do "jogo de símbolos que confunde nossas orientações e nos liberta de uma única interpretação do espaço" (BARBOSA, 2016, 144-145).

Assim sendo, vale destacar que a cartografia como método para pesquisa em artes é um vasto campo aberto para pesquisadores que nela buscam se lançar de maneira rizomática, afinal há uma infinidade de entradas e caminhos possíveis para esses processos de pesquisa e/ou criação artística. Aqui, longe de modelos - afinal, são cartografias! -, vamos destacar algumas possibilidades ricas e potentes, exemplos que devem server como provocações, como instância da pesquisa criativa e subjetiva, feita com rigor científico e com a sensibilidade de quem se deixa levar por práticas criativas e sinestésicas.

De saída, fica evidente a aproximação das cartografias artísticas com pesquisas autoetnográficas, devido a quantidade considerável de pesquisadores em programas de pós-graduação em artes no Brasil engajados em metodologias que partem de experiências em primeira pessoa relacionadas com contextos e reflexões mais amplas. Para Thürler e Woyda (2020),

a auto-etnografia é uma abordagem à investigação e escrita que procura descrever e analisar sistematicamente a experiência pessoal (auto) a fim de compreender a experiência cultural (etno) e tal como é expressa através da escrita, performance, ou outros meios criativos. Esta abordagem vem desafiando formas canônicas de fazer ciência e trata a investigação como um ato político, socialmente justo e consciente. Mais especificamente um investigador utiliza princípios de autobiografia e da etnografia para fazer e escrever auto-etnografia; um método que mistura os propósitos, técnicas e teorias da investigação social - principalmente a etnografia

R. Inter. Interdisc. Art\&Sensorium, Curitiba, v.8, n.1, p. 315 - 330 Jan.- Jun. 2021 
- com os propósitos, técnicas e teorias associadas à escrita de gêneros de vida, especialmente a autobiografia, memórias, e ensaio pessoal, se tornando tanto um processo como um produto. (THÜRLER, WOYDA, 2020, p. 137).

Esse parece ser o caso de Freire (2019), em "Palavra-corpo: uma cartografia fragmentária, enigmas do livro de artista na construção dos espetáculos" (2019), uma cartografia construída por processos teatrais autobiográficos: "[Para mim] A cartografia artística procura mostrar um documento pessoal dos processos que vivencio, compreendendo meu saber-fazer artístico e buscando entender essa virtualização que se insere junto ao corpo nessa reconstrução do imaginário criado. Imaginário esse, compartilhado a partir do que faço e mostro, em partes, através desse corpo que se amplia nessa confluência midiática" (FREIRE, 2019, p. 03). Freire nos diz que seu processo cartográfico se dá pela construção de um mosaico, com fragmentos, referências e partes provindas de vários lugares, registros e atravessamentos do artista que explicam a obra que está sendo produzida. Em sua cartografia, toma como referência o blog de sua autoria, "corpo-palavra" 8 , que funciona como um caderno do artista, um diário de bordo que capta e registra suas impressões ao longo de muitos processos criativos.

Como já expusemos aqui, os aplicativos de geolocalização disponíveis nos aparelhos eletrônicos podem incidir e mudar a maneira como as pessoas se relacionam com o espaço. Memórias afetivas, referências físicas e/ou de memória se transformam, passam a ser em quinhentos metros, vire à direita. Pensando nas possibilidades de utilização desses aplicativos para a criação artística, destacamos duas pesquisas. A primeira de Andres (2013), percorre a cidade de Santa Maria/RS em busca de cartografar e catalogar práticas urbanas artísticas presentes em suas caminhadas pela cidade; a segunda, de Nakano (2015), se debruça sobre as interfaces e possibilidades de interação entre usuários e a cibercartografia, argumentando que a cibercartografia passa de um esquema cartesiano para a co-criação entre usuários e dispositivos, permitindo múltiplas possibilidades. Segundo ela, a transposição do agenciamento tecnológico para uma relação criativa/subjetiva remete às derivas situacionistas de alguns artistas franceses, na década de 1960, em suas práticas insurgentes e criativas em Paris.

Sobre derivas, deambulações e errâncias propostas, direta ou indiretamente, na obra de vários artistas ao longo do tempo, podemos retornar às reflexões e bases históricas presentes na obra de Paola Berenstein Jacques (2012), "Elogio aos errantes", em que a autora irá tomar três momentos distintos na história urbana de Paris para encontrar práticas de cidade desviantes, da mesma forma que observará na obra de João do Rio indícios de uma urbanidade que se sobrepunha às subjetividades de parte dos habitantes da então capital do Brasil, passando por um processo de modernização, conduzido pelo prefeito Pereira Passos.

Jacques (2008), em outra ocasião, irá discutir o termo corpografia como a cartografia situada nas performances corporais dos errantes das grandes cidades, experiências corporais que influenciam a construção da cidade e vice-versa. Nas palavras da autora, "a corpografia seria uma cartografia corporal, ou seja, ela parte da hipótese de que a experiência urbana fica inscrita em diversas escalas de temporalidade, no próprio corpo daquele que a experimenta, e dessa forma também o define, mesmo que involuntariamente" (JACQUES, 2008, p. 51), ou seja, através da corpografia, esses praticantes ordinários da cidade (CERTEAU, 1994) fabulam rotas e relações novas com o espaço.

\footnotetext{
${ }^{8} \mathrm{O}$ blog pode ser acessado https://palavra-corpo.blogspot.com.
} 
Desse modo, a corpografia estudada por Jacques tem forte influência e interesse por interferências artísticas ocorridas em espaços não-convencionais para as artes. Também interessada nos fluxos caminhantes e desviantes que os trabalhos artísticos podem estabelecer fora dos mapas convencionais, Cunha (2016), em sua dissertação, se debruça sobre a performance "Caminhada Silenciosa", da artista Vivian Caccuri, entendendo a potência da caminhar como ação artística.

As intervenções urbanas/performances reunidas no livro-performance "Ações", da pesquisadora e performer Eleonora Fabião (com organização também de André Lepecki) poderiam, também, ser descritas como cartografia artística de práticas microbianas do cotidiano. No livro, vemos performances feitas, entre 2008 e 2015, em algumas cidades ao redor do mundo, em que Fabião impacta rotinas dos transeuntes, ocupantes, cidadãos. As fotografias do livro revelam que a prática de Fabião não necessita de grandes gestos ou grandes estruturas físicas, ao contrário, é na minúcia, no miúdo que se dá sua interação, sua lógica de intervenção no dia-a-dia de quem encontra nos espaços por onde passa e performa. Segundo Lopes (2021), o livro cartografa os fluxos e a efemeridade dos atos realizados por Fabião, mas, não é um mero registro dos ocorridos, a ideia de um livro-performance, seja pelos textos reflexivos presentes, seja pela escolha de imagens, por sua diagramação, dá ao leitor a possibilidade de interagir com a obra independente de ter ou não visto, vivenciado ou mesmo conhecer de antemão as performances da artista.

Depois dessa rápida visada de possibilidades cartográficas artísticas, arriscamos dizer que as práticas da cartografia artística são baseadas em pistas deixadas por alguns autores que romperam o entendimento da cartografia escalar dos mapas. Neste sentido, é sempre salutar recorrer às reflexões de Deleuze, Guattari e Rolnik, mas, também, de Kastrup e Passos - apenas para citar algumas trilhas que os interessados na cartografia [artística] poderiam percorrer -. Por outro lado, a natureza inventiva tão cara aos processos de criação abre inúmeras possibilidades quando pensamos em cartografias artísticas. Portanto, inspirados em Kastrup e Passos, pensamos que seja possível falar em pistas para essa metodologia, que pode (e deve!) ser adaptada aos contextos, pulsões, desejos, sentimentos, preferências, questões, processos de cada pesquisador.

Marília Becker (2017) se propõe a estudar a confluência de linguagens artísticas nos site-specifics que interessam à sua pesquisa, também a relação criada entre obras e público, nestes lugares que não são espaços convencionais de apresentações artísticas. Becker é outra pesquisadora a falar em pistas e referências que contribuem na construção da metodologia de sua pesquisa. Mais uma vez, uma pesquisa que revela a pesquisadora em contato com aquilo que interessa, compartilhando as escolhas e caminhos com quem lê. Ela nos diz:

Assumindo o papel de cartógrafa-pesquisadora, organizo o conjunto de estudos, processos e técnicas experienciadas, no intuito de elaborar um mapa referenciado e polifônico, afinal, embora o percurso tenha sido individual, encontrei muitos companheiros nesse caminho que indicaram saídas e rotas em momentos de fadiga ou quando encontrava-me perdida no espaço (BECKER, 2017, p. 15).

O mapa polifônico mencionado por Becker é atravessado por epistemologias que extrapolam o campo das artes. Nesse sentido, a errância ao lado de autores diversos como Deleuze, Guattari e Miltons Santos estabelece uma narrativa interdisciplinar que enriquece seu trabalho e aponta para outra pista importante que notamos em nossa busca pelas cartografias artísticas, qual seja, a possibilidade de estabelecer elos entre diversos campos dos saberes.

\footnotetext{
${ }^{9}$ A performance pode ser vista aqui: https://youtu.be/Gvk0QKKwg9k.
} 


\section{Considerações Finais}

Por fim, quisemos dizer até aqui, que os mapas tem sido classificados, ao menos, de duas formas: eles poderiam limitar a nossa visão do mundo ou expandi-la. Da primeira forma, o mapa seria considerado apenas como uma ferramenta para reduzir o mundo; da segunda, uma ferramenta que se abre e cria novas potencialidades de mundo, expandem e revelam a qualidade performativa da cartografia, ou seja, ressignificam os mapas, agora, capazes de criar uma visão expandida do mundo, tanto no leitor do mapa como no seu criador.

Sabemos que a aplicação de um método é uma tarefa pessoal, da mesma forma, sabemos que o método certo é aquele que corresponde a ambos contextos, da investigação e do investigador que a conduz, por isso a cartografia não deve ser entendida como uma postura para todos os que procuram e para todos os objetos. Nossa intenção aqui foi a de apresentar uma possibilidade de entendimento da cartografia que, outros pesquisadores, certamente, fariam de forma diferente. Nós mesmos faríamos de forma diferente em outro contexto, em um tempo-espaço diferente. Entendemos que a visão panorâmica do mapa é uma possibilidade de entrada para quem deseja ter uma ideia mais genérica dos lugares que nos interessam, mas, insistimos, contudo, que a experiência das andanças pelos territórios é ferramenta metodológica potente, porque possibilita uma experiência de campo encarnada em Exu, compartilhando com os outros (...), fazendo a vida acontecer nas encruzilhadas e de modo espiral (BENY, 2021, p. 131), olhando nos olhos das pessoas, sentindo os odores e calores proporcionados pela experiência territorial. Experiências ancoradas no real, através de aproximações, pontos em comum, investimentos no olhar encantado com cada um dos vãos das cidades, cantados nas vitrines buarquenas. De um modo geral, o que sugerimos é que você se perca, se encontre, navegue pelos lugares e volte a se perder.

\section{REFERÊNCIAS:}

ANDRES, CAROLINA REICHERT. Cultmap_cartografias artísticas urbanas. 108 f. Dissertação de Mestrado, UFSM, 2013.

BARBOSA, G. S. Diálogos entre cartografia e arte: desconstruções cartográficas na obra de Jorge Macchi. Espaço e Cultura. UERJ, RJ, n. 39, p.139-156, jan./jun. 2016.

BECKER, M. E. Diálogos habitados: cartografia de processos criativos em site-specific. 117 f. Dissertação de mestrado. Unicamp, 2017.

BENY, D. Do terreiro ao teatro: em busca da gestualidade ancestral. Artigos reunidos 2015-2020. São Paulo: e-Manuscrito, 2021. Edição do Kindle.

BESSE, Jean-Marc. Ver a terra: seis ensaios sobre a paisagem e a geografia. Tradução de Vladimir Bartalini. São Paulo: Perspectiva, 2014.

BOETTCHER, C. M. E. A. Cartografando memórias, vivências e sensibilidades: A Arte-CidadeUniversidade/UFRGS. Dissertação (Mestrado). Universidade Federal do Rio Grande do Sul, Faculdade de Arquitetura, Programa de Pós-Graduação em Planejamento Urbano e Regional, Porto Alegre, 2018.

BOURCIER (Org.). La Sérendipité dans les sciences, les arts et la décision. Actes coloque. Paris, Éditions du CNRS, 2009.

CAQUARD, Sébastian. Cartography I: Mapping Narrative Cartography. Sage Progress Report. Progress in Human Geography. Concordia University, Canadá, 2011, p. 135-144. 
Cartographies II: Collective Cartographies em Social Media Era. Progress in Human Geography, v. 38(1) 2014, p. 141-150.

Cartography III: A post-representational perspective on cognitive cartography. Progress in Human Geography, v. 39(2), 2015, p. 225-235.

CERTEAU, M. A invenção do cotidiano: 1 - Artes de fazer. Petrópolis: Vozes, 1994.

COLLING, L. A vontade de expor: arte, gênero e sexualidade. Salvador: EDUFBA, 2021.

COSGROVE, Denis. Art and Mapping: An Introduction. In: Cartographic Perspectives. Number 53, Winter 2006.

DELEUZE, G.; GUATTARI, F. Capitalismo e Esquizofrenia. Mil Platôs, Volume 01. São Paulo: Ed. 34, 2011.

Capitalismo e Esquizofrenia. Mil Platôs, Volume 5. São Paulo: Ed. 34, 2012.

Mille Plateaux. Paris: Éditions de Minuit, coll. "Capitalisme et Schizophrénie”, 1980.

DIBBIE, P. La Passion du regard: essai contre les sciences froides. Paris, Éditions Métailié, 1998.

EVENO, C. L'hypothèse de la Ville. Revue internationale de la pensée critique, n.21, 2001, pp. 5358.

FABIAO, Eleonora; LEPECKI, André (orgs.). Ações. Rumos Itaú Cultural, Rio de Janeiro, 2015.

FIALHO, D.M. I Seminário Arte e Cidade. Salvador. PPG-AU - Faculdade de Arquitetura / PPG-AV - Escola de Belas Artes / PPG-LL - Instituto de Letras UFBA, maio de 2006.

FILHO, K. P.; TETI, M. M. A Cartografia como método para as ciências sociais e humanas. In: Barbarói. n. 38, Santa Cruz do Sul/RS, jan-jun 2013, p. 45-59.

FREIRE, B. T. B. PALAVRA-CORPO: uma cartografia fragmentária, enigmas do livro de artista na construção dos espetáculos. 56 f. Dissertação de mestrado, UFPA, 2019.

GEERTZ, C. A Interpretação das Culturas. Rio de Janeiro: LTC, 1989.

GUATTARI, F.; ROLNIK, S. Micropolítica: Cartografias do Desejo. Petrópolis/RJ: Editora Vozes, 1996.

GUATTARI, F. Schizoanalytic Cartographies. Translated by Andrew Goffey. New York: Bloomsbury, 2013.

HADDOCK-LOBO, R. Arruaças: uma filosofia popular brasileira. Rio de Janeiro: Bazar do Tempo, 2020.

HATZFELD, M. Zoner, une errance dans l'émergence. In: ANDEL, P. V. ; D.

JACQUES, P. B. Cenografia e Corpografias Urbanas: Espetáculo e experiência na cidade contemporânea. Revista Observatório Itaú Cultural/OIC, São Paulo, n.5, p. 47-57, abril/junho 2008).

JACQUES, P. B. Elogio aos errantes. Salvador: EDUFBA, 2012.

KASTRUP, V.; PASSOS, E. Cartografar é traçar um plano comum. Fractal, Revista de Psicologia, v.25 - n.2, p. 263-280, Maio/Agosto, 2013.

KASTRUP, V.; PASSOS, E.; ESCÓSSIA, L.. [org.] Pistas do Método Cartográfico: PesquisaIntervenção e produção da subjetividade. Rio de Janeiro: Editora Meridional, 2015.

O mapa como relato - artigo da revista $\mathrm{Ra}$ ' e $\mathrm{Ga}$ - $\mathrm{O}$ espaço geográfico em análise. Curitiba, v.30, abr/2014, p.41-64.

LOPES, Elisabeth Silva. Ações de Eleonora Fabião. In: Hemispheric Institute, 2021:

https://hemisphericinstitute.org/pt/emisferica-14-1-expulsion/14-1-book-reviews/acoes-de-eleonorafabiao.html [acesso em 13 de maio de 2021].

MASSEY, Doreen. Pelo Espaço: uma nova politica da espacialidade. Editora Bertrand Brasil, Rio de Janeiro, 2008.

MOURA, C.B.; HERNANDEZ, A. Cartografia como método de pesquisa em arte. XI Seminário de História da Arte, n.2, 2012. 
NASCIMENTO, W. F. do. As filosofias vagabundas. In: SIMAS, L. A.; RUFINO, L.; NAVARRO, Lúcia. Esquizoanálise. In: https://www.ufrgs.br/e psico/subjetivacao/ espaco/esquizoanalise.html. Acesso 05 mar 2021.

NUNES, Rodrigo. Liderança Distribuída. PISEAGRAMA. Belo Horizonte, número 09, 2016, p. 1019.

PERES, R. S; BORSONELLO, E. C.; PERES, W. S. A esquizoanálise e a produção da subjetividade: considerações práticas e teóricas. Psicologia em Estudo, v. 5 n. 1, 2000, p. 35-43.

RENA, N. S. A.; SÁ, A. I. J. A.; LOPES, M. S. B.; FRANZONI, J. Á. Grupo de Pesquisa Indisciplinar: Método, Ativismo e Tecnopolítica na Defesa dos Bens Comuns Urbanos. In: Congreso Internacional Contested_CITIES, 5., 2016, Madrid. In: http://contested-cities.net/workingpapers/wp-content/uploads/sites/8/2016/07/WPCC-165524-RenaS\%C3\%A1BrandaoFranzoniGrupodePesquisaInterdisciplinar. Acesso em 11 de março de 2021.

RIFFAUD, Thomas. Flânerie sociologique une méthodologie adogmatique. SociologieS. 15 novembre 2018. In: http://journals.openedition.org/sociologies/8673. Acesso em 11 março de 2021. ROLNIK, Suely. Cartografia Sentimental: transformações contemporâneas do desejo. Porto Alegre: Sulina, editora da UFRGS, 2011.

ROSA, J.G.O Espelho. In: João Guimarães Rosa - Primeiras Estórias. Editora Comemorativa 40 anos, Rio de Janeiro: Nova Fronteira, 2006.

SANTOS, Milton. Por Uma Outra Globalização. Rio de Janeiro: Ed. Record, 2006.

THÜRLER, D.; WOYDA, D. Os efeitos marginalizadores da heteronormatividade em "The boys in the band". Revista Apotheke, v. 6, n. 3, p. 128-142, dezembro 2020. 